\title{
Host- microbiome interactions in a changing sea: the gill microbiome of an invasive oyster under drastic changes in temperature
}

\author{
Yahala Rina-Dor ${ }^{1}$, Yehuda Benayahu ${ }^{1}$, Leah Reshef ${ }^{2}$, and Uri Gophna ${ }^{2}$ \\ ${ }^{1}$ University of Tel Aviv \\ ${ }^{2}$ Tel Aviv University
}

December 18, 2020

\begin{abstract}
The gill tissue of bivalve mollusks hosts rich symbiotic microbial communities that may contribute to the host wellbeing. Spondylus spinosus is a Lessepsian invasive oyster to the eastern Mediterranean Sea that has become highly abundant, while constantly expending its range northwestward. Using $16 \mathrm{~S}$ rRNA gene amplicon sequencing we examined how temperature affects the gill microbiota of S. spinosus, and the oysters themselves, in a series of experiments: exposing the oysters to the current annual seawater temperature range; to the colder temperature of the western Mediterranean Sea; and to elevated temperature as predicted under global warming scenarios. The bacterial genus Endozoicomonas dominated the communities of the S. spinosus, mainly upon exposure to winter-like temperatures. Exposure to elevated seawater temperature resulted in a significant change in the bacterial communities, while the oysters maintained normal functioning, suggesting that the oyster may survive a seawater warming scenario. Exposure to colder winter temperature typical to the western Mediterranean Sea resulted in health deterioration of the oysters, emergence of opportunistic pathogens, and a decline in the relative abundance of Endozoicomonas, suggesting that S. spinosus might not survive in the cold western Mediterranean Sea. The findings indicate that gill bacteria are greatly affected by temperature, which could consequently restrict the range expansion of this and other invasive oysters.
\end{abstract}

\section{Hosted file}

Host- microbiome interactions in a changing sea the gill microbiome of an invasive oyster under drastic available at https://authorea.com/users/383556/articles/499434-host-microbiome-interactionsin-a-changing-sea-the-gill-microbiome-of-an-invasive-oyster-under-drastic-changes-intemperature

\section{Hosted file}

Table 1.xlsx available at https://authorea.com/users/383556/articles/499434-host-microbiomeinteractions-in-a-changing-sea-the-gill-microbiome-of-an-invasive-oyster-under-drasticchanges-in-temperature 


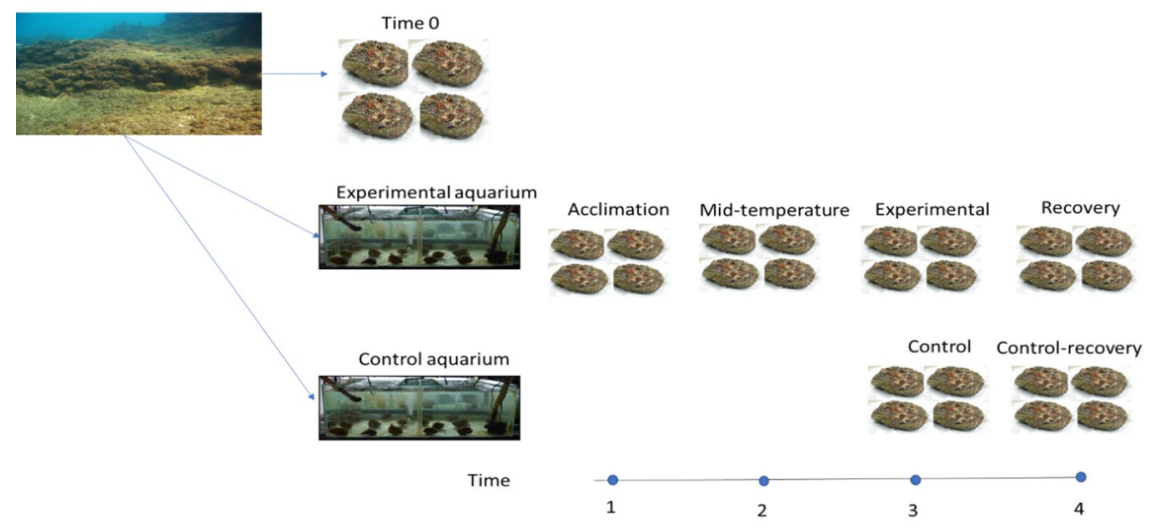

(a)

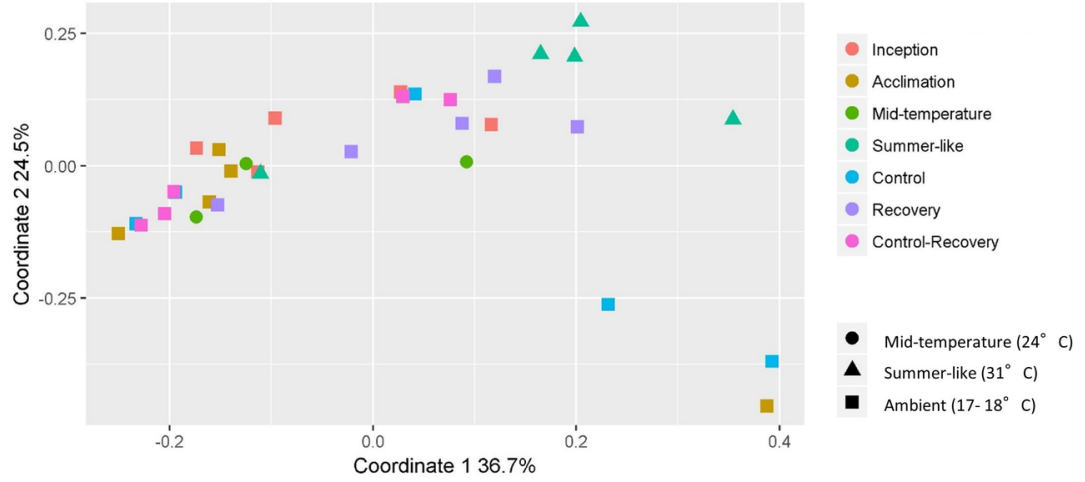

(b)

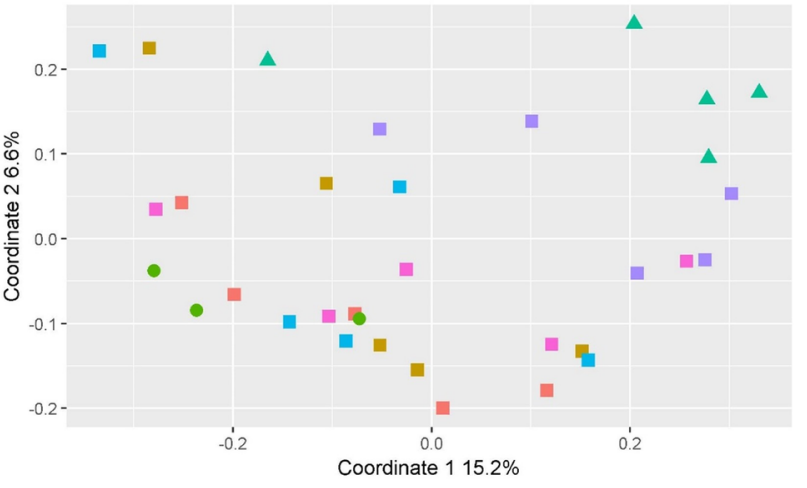




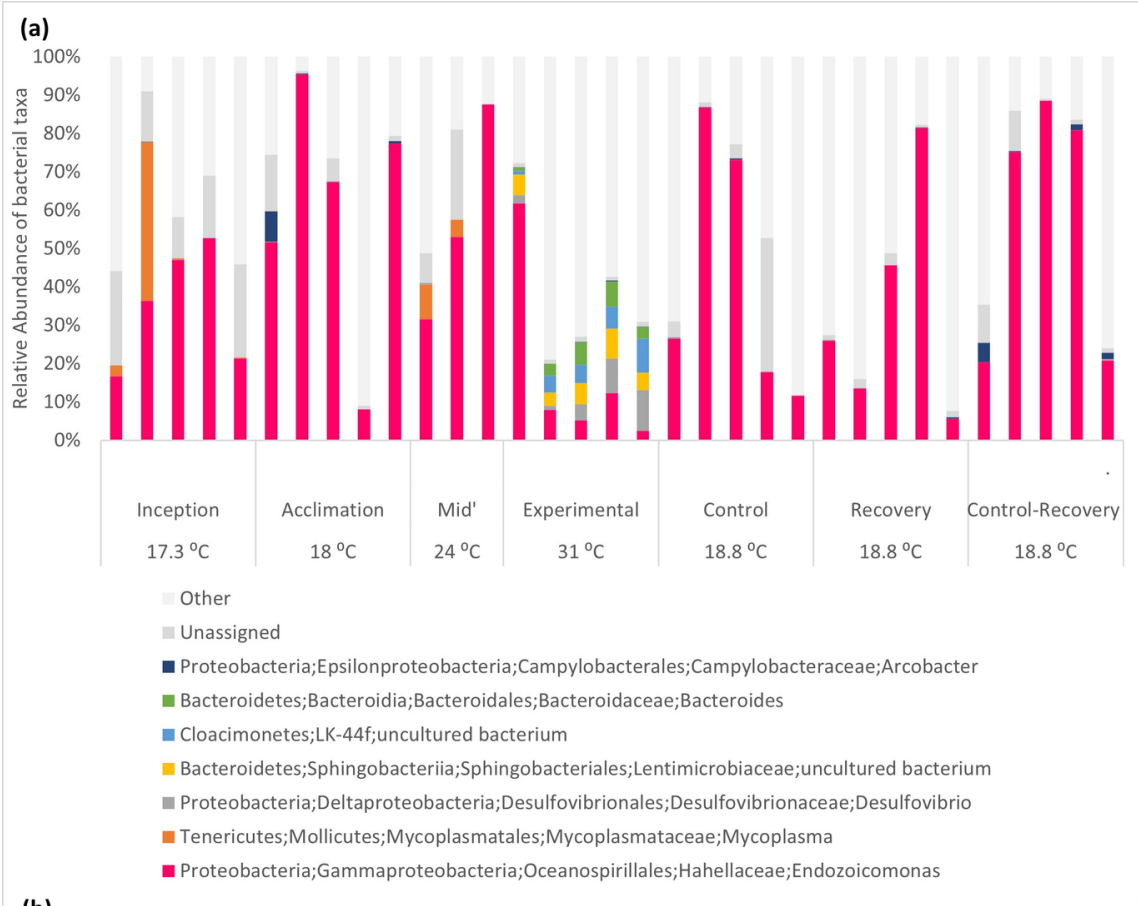

(b)

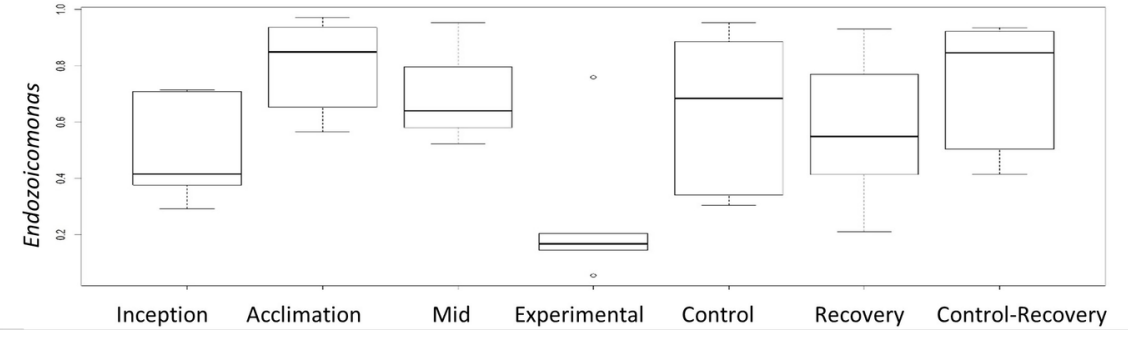



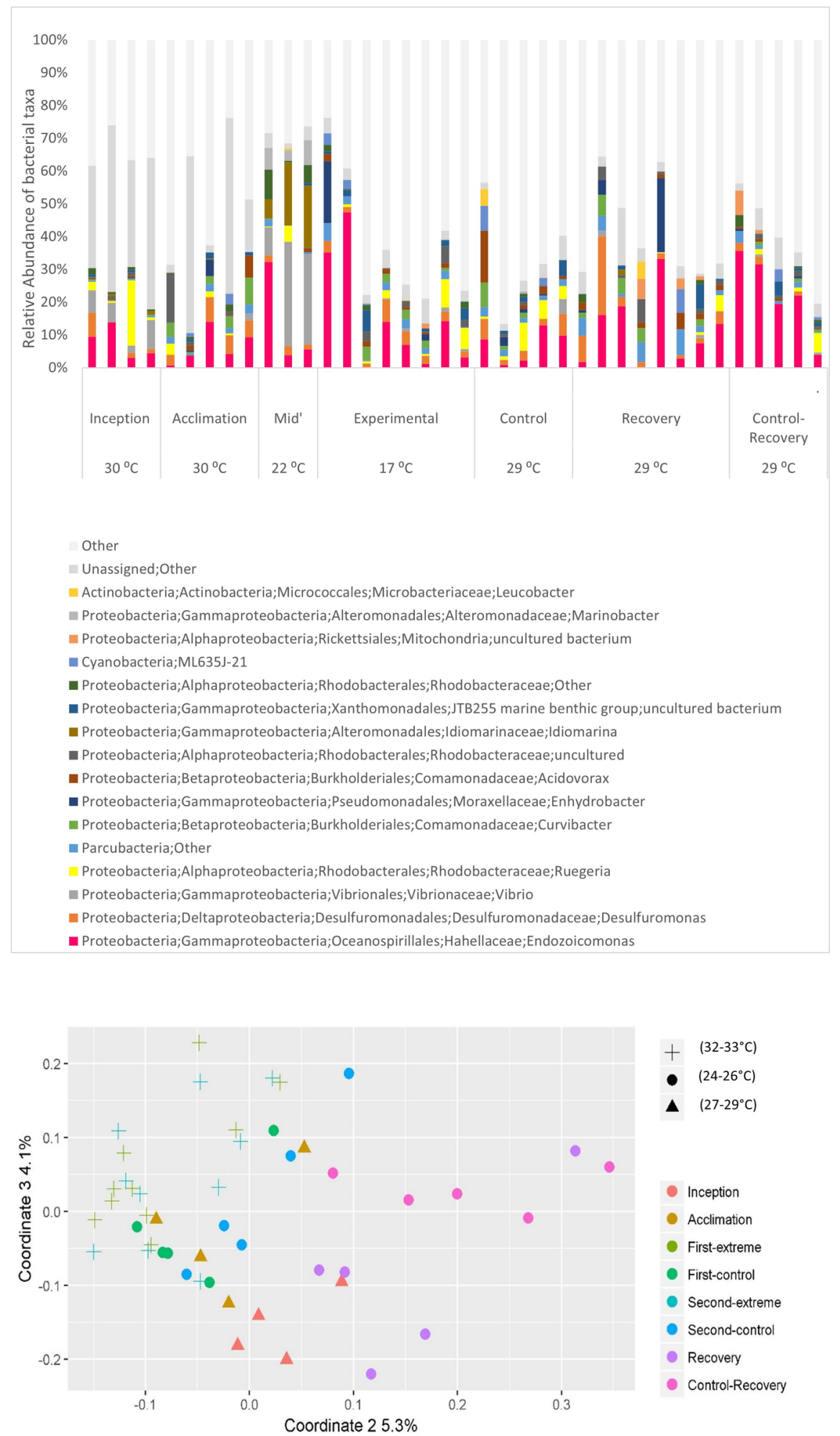


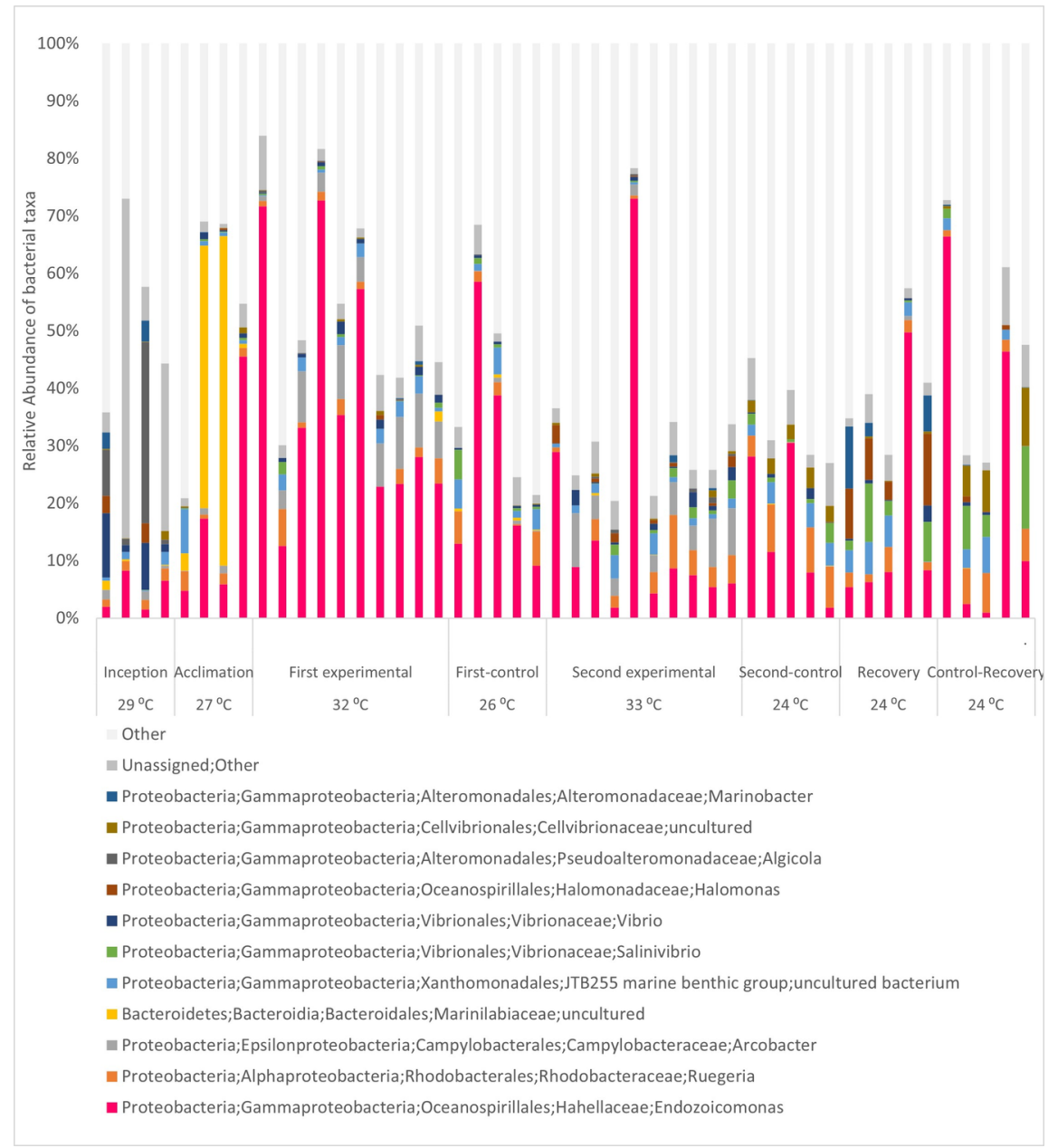




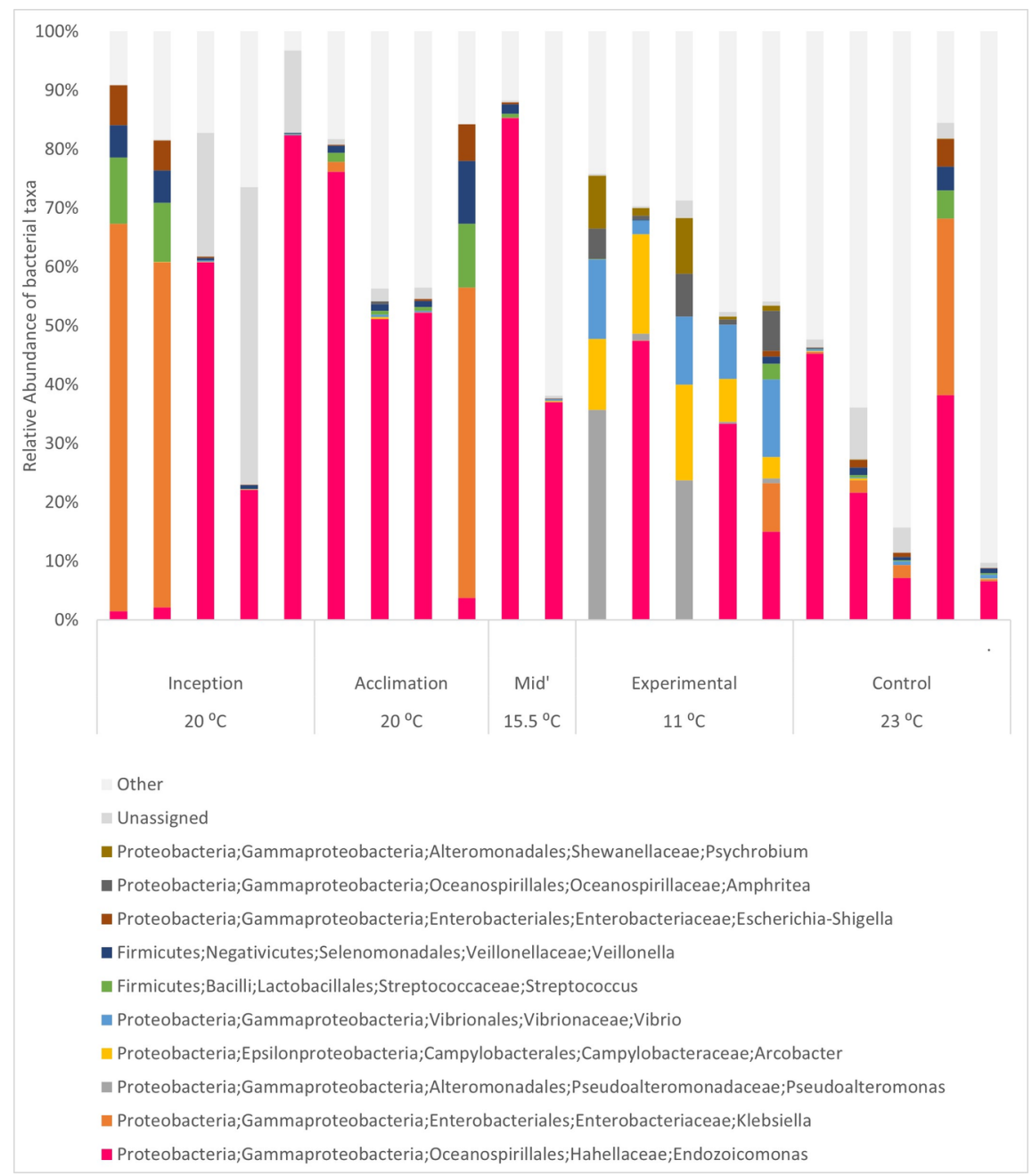

